\title{
On the Planning and Design of Jingdezhen as a Center of Tourism Under the Influence of "Slow City" Model
}

\author{
Xiaoli $\mathrm{Yu}^{1, \mathrm{a}}$, Ying $\mathrm{Li}^{2, \mathrm{~b}}$ and Linxi $\mathrm{Li}^{3, \mathrm{c}}$ \\ ${ }^{1}$ Design and Art School, Jingdezhen Ceramic Institute, Jingdezhen, Jiangxi Province, China \\ ${ }^{2}$ International School, Jingdezhen Ceramic Institute, Jingdezhen, Jiangxi Province, China \\ ${ }^{3} 333$, Tianfu Two Street, New and High-Tech Zones, Chengdu, Sichuan Province, China \\ a2006yuxiaoli@163.com, beagle05fly@163.com, 609975704@qq.com
}

Key Words: "Slow City" model, Jingdezhen, Tourism City, Urban Planning

Abstract: Originated in Italy, "slow city" model is a newly urban development model. The snail as a city's logo well reflects the value of "slow city" model. Slow speed is a spiritual pursuit of life for mankind. The number of cities all over the world, entitled "slow cities", is increasing while the concept of "slow city" model is gradually becoming universally acknowledged. Based on this concept, the thesis analyzes the cultural characteristics of Jingdezhen as a tourism city, trying to make Jingdezhen a city suitable for living in. Hopefully it enlightens readers about the urban planning and design of small and medium sized tourism cities under the influence of the "slow city" model.

\section{Introduction}

Mr. Klaus R. Kunzmann, the professor at the School of Planning at the Universität Dortmund, Germany, once pointed out that "slow city" is a comfortable, pleasant and safe city suitable for walking, which simultaneously respecting the historic roots of the place, protecting the natural environment and making full use of energy resources. With the rapid economic development of China, ever increasing numbers of citizens have become impatient and irritable. On the one hand, the rapid progress made by China's urban development has brought convenience. On the other hand, it has been unconsciously eliminating the unique traits of each city. The concept of "slow city" model helps to preserve the characteristics of each city. As for the small and medium sized tourism cities with regional characteristics, "slow city" model offers them an opportunity to develop.

\section{The origin of "slow city" and the concept of "slow city"model}

\section{The origin of "slow city"}

"Slow city" can also be called city of slow speed or city of slow pace. It originated from Burano, an Italian city with about 15,000 population. It is a new urban pattern that slows the pace of life. It advocates the return to the essence of life and pursues a new mode of urban life that is diverse, inclusive, and human-centered. It initiates a green, sustainable, leisurely and comfortable lifestyle that represents a wonderful state of life. It has unique regional cultural aspects, delicious food, healthy environment, sustainable economy and a relaxed and comfortable community life. According to these foreign cities that can be classified "slow cities", it should be a city that has beautiful environment, hiking areas and green space everywhere. Its local traditional productions, food, organic agriculture, and special technologies are strongly supported by relevant government departments and the shops selling local specialties are supported as well. Its local residents are friendly and hospitable, living a life of leisure, advocating green technology and promoting conservation of the environment. In short, it is a better urban mode, more suitable for people to live and travel. The lifestyle of "slow city", since its rise, has been sought after by many supporters, especially government officials and urban scholars. 
There seems to be a world trend to develop cities into "Slow cities". In a short span of ten years, the "slow city movement" has swept across the entire European continent, and to some degree the whole world. In 2010 Yaxi village, located in Gaochun county, Nanjing city, Jiangsu province in China was officially awarded the title of "International Slow City". As China's first slow city emerged, "slow city movement" kicked off throughout China.

\section{The concept of "slow city" model}

The concept of "slow city" model opposes modern urban lifestyle that blindly pursues high speed. It reflects on the previous development patterns of cities and demonstrates a correct way of life. Its aim is to achieve harmony between city and its people and to create rest space for human beings amid the process of rapid development. "Slow speed" doesn't mean laziness or degeneration, instead supplying happiness and pleasure to visitors and residents alike. It makes people slow down in a particular space and environment, so that they can experience life, enjoy it, soak it in, reflect on it, and return to a natural state of living. "Slow city" model actually combines "fast speed" with "slow speed", so as to achieve the real sense of the rapid urban development. Undoubtedly, the core concept utilized in the construction of "slow cities" is compactness, wisdom, ecology and humanistic spirit. "Slow City" model offers people a relaxed and pleasant lifestyle that can help to solve the energy and environmental problems under current situation and to achieve environmental protection and sustainable development. The concept includes the following three aspects.

\section{Aspect one ---- a mode of urban development suitable for living}

"Slow city" model advocates place suitable for living where the environment, facilities and other aspects are good for health. In terms of the environment, it proposes to build a place where human beings and nature can live in harmony. It requires human beings to respect the laws of nature, to reduce noise and environmental pollution, to increase the number of green spaces and walking areas, to limit the usage of cars, and to promote the application of environmental protection technology. In terms of daily life, citizens should be friendly and hospitable. They should develop good habits shedding the need to rush around, instead of living a luxurious and wasteful life, depleting natural resources and polluting the environment. They should retrieve the essence of life and ponder the true meaning of life in their spare time.

\section{Aspect two --- the protection of traditional culture and the inheritance of its characteristics}

Put forward in the context of globalization, the "slow city" model underlines the importance of protecting local traditional culture and its characteristics which are gradually disappearing. To build a "slow city" is to respect tradition, to preserve the lifestyle maintained in traditional communities and to build a green ecological homeland. In the development process of the "slow city", the city's unique characteristics are strictly maintained. According to many current policies of urban construction, old buildings and houses should be torn down. The "slow city" model instead encourages the restoration urban protection and the inheritance of local history and culture.

\section{Aspect three ---- economic benefits}

In the pursuit of slow life, people should show more respect for nature and ecology on the basis of economic development. All the elements, such as traditional food, unique crafts, beautiful scenery, friendly citizens, will lay the foundation for high quality tourism in "slow city". If tourism in "slow city" develops well, ever more tourists will flock to the destination and with them bring considerable economic benefits. In such a "slow city", both tourists and local people can feel free to enjoy the local traditional culture, delicious local food and local handicrafts and specialties. In the "slow city", they will feel the harmonious living atmosphere around them. 


\section{The idea of planning and design of Jingdezhen as a tourism city under the influence of the "slow city" model}

Jingdezhen is one of the most notorious medium sized tourism and industrial cities in China. In a 2013 comprehensive evaluation on the development of Chinese leisure cities, Jingdezhen was titled "The Ceramic Leisure Capital Among 2013 Chinese Distinctive Leisure Cities". Jingdezhen is famous for its long history of porcelain-making and exquisite ceramic industry throughout the world. It also holds the title of Millennium Ceramic Capital with its unique cultural features, which can be seen when visiting its scenic spots, particularly Ancient Kiln and Yaoli Town. It is a typical city in Southern China, surrounded by mountains and rivers. Moreover, Jingdezhen attracts more and more visitors and those who would like to inhabit here through its slow, natural and peaceful lifestyle.

The vigorous development of "slow cities" around the world indicates that the concept of "slow city" model meets people's demand for this type of lifestyle. The traditional culture in Jingdezhen also embodies this "slow" culture. The potential developmental trend of this city coincides with the concept of "slow city". The application of "slow city" model into Jingdezhen can make Jingdezhen develop more smoothly and make it a city more suitable for people to live and travel. After analyzing the characteristics of Jingdezhen, I would like to put forward some suggestions on the planning and design of Jingdezhen as a center of tourism, combining the"slow city" model with local tourism and culture.

\section{The style of landscape architecture}

Each city has its own historical architecture, which witnessed the history of that city. The historical architecture with profound cultural characteristics and distinctive features in style is not only an important part of the landscape architecture, but also a beautiful landscape for the city. There are many historical buildings in Jingdezhen, such as buildings built in the Ming and Qing Dynasties in the district of Sanlu Miao, antique-looking neighborhood in Doufu Lane, unified antique-looking architectural complex in Huizhou style, stilted buildings in Liujia Lane, Zhejiang Road. Its government and residents should protect all these historical buildings and try to restore them completely to former state. In terms of materials of construction and decoration, ecological building materials should be used to reduce the negative impact on human beings and environment to the minimum. In terms of decoration style, the materials related with Jingdezhen ceramic culture should be selected, such as bricks from kilns, scraps of broken ceramics, etc. In addition, another cultural heritage in Jingdezhen is the ancient kilns. Therefore, the most important thing is to protect and to renovate all these official kilns, private commercial kilns, and wood-fired kilns. When people take part in repairing these ancient buildings, they will recognize the distinctive cultural features in Jingdezhen step by step.

\section{Construction of green transportation}

The transportation in Jingdezhen is far from satisfaction. The citizens' consciousness towards traffic is rather weak, and the planning of public transportation is too simple. As a result, the traffic is always in a mess in rush hours with traffic jams everywhere and horns screaming all around. If we want to stop this from happening, things should be done as follows. First, reduce the number of motor vehicles. The speed should be slowed down to no more than $20 \mathrm{~km} / \mathrm{h}$. No honking in the central area. Second, attach importance to sidewalk and cycle track. Advocate walking and cycling. Design the road layout reasonably according to natural landscape surrounded by in order to slow down walkers' walking pace.Third, design road landscapes spreading "slow city" culture. Put up guide boards and public art works alerting people to move slowly. Fourth, build more 
multi-storey parking lots and underground parking lots. As a tourism city, there are many tourist buses and self-driving cars other than local vehicles. Therefore, larger parking lots needs to be built. Underground parking lots in downtown also need to be built for the convenience of local citizens to take part in unique cultural activities.

\section{Promotion of craftsmanship and carrying forward food culture}

Jingdezhen has preserved complete porcelain-making industry. Thus, it has attracted the ceramic enthusiasts from all over the world and those pursuing the creation of arts, which brings new vitality for the Millennium Ceramic Capital. As for culture, Jingdezhen's food is unique, such as cakes containing soda, cakes in the shape of dumpling, cakes blended with pepper. Compared with modern cuisine, traditional food in Jingdezhen is more simple and original. The government should strongly support the promotion of handicrafts and carry forward food culture in Jingdezhen. Linking together the ceramic handicraft markets and the traditional food stalls can diversify markets and visitors are more likely to experience the local culture through browsing art works and tasting food in such markets. And besides, the government should lengthen roads of markets and increase routes, because the current roads are too short and markets are too small to satisfy visitors. Roads should be designed in different shapes, increasing more turning points and intersections instead of linear roads. By this means, people walk slowly and enjoy the culture in Jingdezhen. Moreover, markets should provide more notice boards that match the tour routes to avoid the situation of collision or crowding among visitors. In the markets, stalls selling handicrafts and traditional food should be mixed and matched to reduce visitors' aesthetic weariness.

\section{Construction of a slow tourism city}

A slow tourism city makes people feel relaxed on the road. We can attempt to make Jingdezhen a slow tourism city by building eco-tourism resorts, setting up porcelain-making showrooms, amateur archaeological centers, tea rooms, coffee shops, establishing landscapes where people can be totally immersed. On the basis of "slow city" model, new tourism projects with ceramic features should be developed as well. With unique landscape, exquisite ceramic culture, coupled with interesting tourism projects, visitors will lower down the hurried pace while wearing comfortable cotton and linen clothes in Jingdezhen. People will find the essence of life on journey when changing fast pace of traveling into slow one.

\section{Planning and design of Jingdezhen as a center of tourism under the influence of "slow city" model}

In Jingdezhen, we can see variety of shops selling ceramics. Craftsmen make porcelain quietly. There are famous markets selling ceramic handicrafts, cafes and tea-houses with distinctive art styles, Sanbao Village which is isolated from downtown area and so on. People prefer to sit down, listening to light music, reading books, drawing pictures and writing calligraphy. Many people consider this tourism city as a place fit for the elderly. The city also attracts freelances from all over the world who seek quiet place to live and to create art works, where the air is fresh and life is not stressful. Many visitors have expressed that they have longed for this kind of lifestyle. All these reflect the desire of majority who want to live a rural idyll.

With the rapid development of Jingdezhen, its original quietness is fading away now. Regional features are constantly weakening along with the construction of high-rise buildings and busy streets. Traces of traditional culture are being gradually replaced by modern elements and its local differences are no longer distinctive. This phenomenon should be paid high attention to by the government and its people. Therefore, some personal opinions about planning and design of Jingdezhen are put forward. 


\section{Landscape -- the protection for existing plants}

Protecting the diversity of plants is essential because the plants in natural environment are the most stable ecosystems. For the natural plants in Jingdezhen, excessive reconstruction and design is not necessary. When designing the plants, we should give priority to the protection part, trying to remain original. According to the "slow city" model, the aim of "slow" landscape design is to show the real and inner beauty of nature to its audience.

\section{Site -- diversification of design}

Tourism cities mainly provide tourists with good place to release their stress and enjoy their life of leisure. One of the most important concepts of "slow city" model is to advocate a slow pace of life.Therefore, in terms of design, the number of recreational trails, bicycle lanes, green space and activity place should be added to allow visitors to take the initiative to slow down when playing.

\section{Culture -- search for the regional culture characteristics in Jingdezhen}

Every slow city has its unique history and culture while the idea of "slow city" is to inherit traditional culture and regional culture. In order to protect local culture and its features from disappearing under the background of globalization and to make visitors appreciate strong humanistic spirit while enjoying beautiful scenery, the design plan of slow city landscape should focus on seeking the local traditional culture and regional characteristics and applying these important elements into the design. On the one hand, the application of Jingdezhen traditional culture and its local characteristics into the design inherits its cultural traditions, so that visitors can be exposed to the customs that ancestors left behind thousands years ago. On the other hand, its unique ceramic characteristics can be distinguished from other regions. Traditional humanistic landscape should be protected in sustainable development. In particular, we should explore and inherit local culture, protect the traditional Chinese porcelain-making industry, protect the intangible cultural heritages like local folk festivals, and carry on the humanistic spirit of perseverance.

\section{Ecological space -- region with distinctive feature}

Generally, "slow"tourism city nestles under mountains and near rivers on a small scale.Thus, in the landscape design, we should try to explore local features and take advantage of its natural beauty, to protect the natural environment and put it in the first place. In order to make better use of its ecological characteristics,we should create unique ecological space in that region with "slow city" model. We should attach importance to the development and protection of its ecological environment, We should develop green ecological agriculture and preserve its traditions. We should rebuild green ecology and inherit its culture as well. Applying this special idea of "slow city" model into landscape planning and design helps to build a green and eco-friendly space. Specific plannings are as follows:

Firstly, while improving local infrastructure, we should try to preserve the authenticity of local culture. The original ecology and its residents' belongingness to the region provides the basis for tourists' "slow" experience.

Secondly, we should take the interests of its citizens into consideration and control the impact of foreign business. We should avoid the destruction of the local humanistic landscape when creating ecological space.

Thirdly, we should control the bearing capacity of tourists so as not to be too crowded to destroy the original ecological space. "Slow city" model tries to create places where people live in harmony with mankind and with nature. Hence, we should maintain and build a comfortable and pleasant green environment.

\section{Conclusion}

The action of applying "slow city" model into the development of Jingdezhen and of actively participating in "slow city" movement. On the one hand, it can help to build Jingdezhen an ecological city with low carbon emissions, to provide its residents with safe, convenient, 
comfortable, beautiful, ecological environment to live in, and to enhance the sense of happiness. On the other hand, it is conducive to the protection of local cultural characteristics, to the inheritance and continuation of local history, to the creation of a unique slow tourism city. It is still worthy studying how to effectively integrate the "slow city" model with the development of Jingdezhen, how to strengthen the construction in traffic, sewage, landscaping and to enrich cultural and leisure items and how to increase people's awareness towards "slow city" model.

\section{References:}

[1]kongjian Yu, Art of Survival: Positioning Contemporary Landscape Architecture Design.Beijing:China Architecture\& Building Press(2006).

[2]Melby Cathcart, Practical Application of Landscape Design. Zhang Ying, Li Yong translated Beijing:Machinery Industry Press(2005).

[3]Liangjuan Culture. World Impression:Leisure Travel in Slow Cities. Longmenshuju (2013).

[4]Luan Xiqin, "CittaSlow leading City New Life: Sidelights of Italy City Life". World Science. Vol. 2 (2008), pp. 39-41

[5]Zhu Xiaoqing, Zhen Feng, Jiang Yueting, "The development of Slow City Abroad and the Enlightenment for the development of China's City”. Urban Studies. Vol.4(2011), pp. 84-90.

[6]Zhang Jun, Lu Fengping, GuFeng, "Connotation and Construction of the Attraction System of Slow City tourism”. Urban Problems. Vol.9(2011), pp. 26-31

Note: The thesis is the stage result of the 2016 Jiangxi Province culture and arts and science planning general project "Tourism Cities from the Perspective of 'Slow City' -- Study on the Planning and Design of Fuliang County in Jingdezhen” (YG2016049) 